\title{
Study of the efficacy of a Streptococcus uberis mastitis vaccine against an experimental intramammary infection with a heterologous strain in dairy cows
}

\author{
R. Collado, ${ }^{1,2}$ C. Montbrau, ${ }^{1}$ M. Sitjà, and A. Prenafeta \\ Hipra Scientific S.L.U., Avda. La Selva 135, 17170 Amer, Spain
}

\begin{abstract}
Streptococcus uberis is a worldwide pathogen that causes intramammary infections in dairy cattle. Nevertheless, commercial vaccines are currently not available and measures to control S. uberis mastitis are limited to the implementation of good management practices. The aim of the present study was to evaluate the efficacy of an $S$. uberis subunit vaccine against bovine mastitis (Laboratorios Hipra S.A., Amer, Spain) administered precalving against an experimental intramammary challenge with a heterologous $S$. uberis strain in dairy cows postcalving. With this objective, 25 gestating Holstein-Friesian heifers were randomly assigned to 1 of 2 groups: group $1(\mathrm{n}=13)$, vaccinated by intramuscular route with the vaccine, and group 2 ( $\mathrm{n}=$ 12 ), vaccinated by intramuscular route with phosphatebuffered saline as a control group. Both groups were immunized 60 and $21 \mathrm{~d}$ before the expected parturition date (75 and $36 \mathrm{~d}$ before challenge). Fourteen days after calving all cows were challenged by intramammary infusion of 100 colony-forming units of a heterologous $S$. uberis strain in 2 quarters per cow. Then, challenged quarters were monitored for clinical signs of mastitis, bacterial count, and somatic cell count for the following $21 \mathrm{~d}$. Rectal temperature and daily milk yield per cow were also assessed. Results showed that all challenged quarters developed clinical mastitis. Nevertheless, vaccination significantly reduced the clinical signs of mastitis, bacterial count, rectal temperature, and daily milk yield losses after the intramammary infection and significantly increased the number of quarters with no bacterial isolation and somatic cell count $<200,000$ cells/mL at the end of the study (d 19, 20, and 21 after challenge). To confirm the efficacy of this vaccine, further studies under field conditions are needed.
\end{abstract}

Received March 28, 2018.

Accepted July 17, 2018.

${ }^{1}$ These authors contributed equally to this work.

${ }^{2}$ Corresponding author: rosa.collado@hipra.com
Key words: Streptococcus uberis, mastitis, vaccine, dairy cow

\section{INTRODUCTION}

Streptococcus uberis is one of the major causative pathogens of clinical and subclinical mastitis in dairy cattle. It has been estimated that it is responsible for 14 to $26 \%$ of clinical mastitis cases in countries such as Canada, the United States, and the Netherlands and is the main cause of clinical mastitis in New Zealand and Australia (Hogan and Smith, 1997; Wang et al., 1999; McDougall et al., 2007). Historically, S. uberis has been classified as an environmental pathogen, as the control of contagious mastitis pathogens with the use of good management practices has a limited effect on the prevalence and incidence of environmental S. uberis mastitis (Leigh, 1999). However, in recent years, the development of new molecular typing studies has evidenced that there is also direct transmission and predominance of particular strains in some herds (Zadoks et al., 2003; Davies et al., 2016; Archer et al., 2017). Related to these observations, recent studies described differences in virulence among $S$. uberis isolates in vivo, classifying the strains into host-adapted strains, which may be capable of cow-to-cow transmission, and nonadapted strains, associated with transient infections of environmental origin (Tassi et al., 2013). Afterward, the same group demonstrated that resistance against macrophage killing and the ability to adhere to the mammary epithelial cells were in vitro traits that correlated with S. uberis virulence found in vivo (Tassi et al., 2015). Biofilm formation has been described as one of the important virulence factors of some strains of $S$. uberis (Varhimo et al., 2011). Moreover, Crowley et al. (2011) demonstrated that the transition from planktonic to biofilm growth in the $S$. uberis 0140J strain correlated with an upregulation of several gene products that have been shown to be important for pathogenesis.

In parallel with the abovementioned investigations, different approaches have been made in the design of experimental vaccines against $S$. uberis by several au- 
thors. For instance, protection of the mammary gland against infection with a homologous $S$. uberis strain was achieved by multiple intramammary vaccinations with killed bacterial cells (Finch et al. 1994). The same authors observed that a combined vaccination with live S. uberis, subcutaneously administered, and intramammary infusion of a bacterial extract also protected against a homologous challenge. Unfortunately, this method was less effective when a heterologous strain was used in a challenge (Finch et al., 1997). A subunit vaccine based on the bovine plasminogen activator (PauA) from S. uberis conferred 37.5 to $62.5 \%$ heterologous protection from clinical disease (Leigh et al., 1999).

Despite the different approaches in the design of experimental vaccines against $S$. uberis, there is still a lack of commercially available vaccines. Therefore, the aim of the present study was to assess the efficacy of a new vaccine against the bovine mastitis caused by S. uberis. With this purpose, first, the vaccine strain was selected. Then, the vaccine antigen (BAC) was analyzed to identify immunogenic components. Finally, the efficacy of the vaccine administered precalving was tested against an experimental intramammary challenge in dairy cows postcalving.

\section{MATERIALS AND METHODS}

\section{Bacterial Strains}

Streptococcus uberis strains SU1H, SU2H, SU4H, SU5H, SU6H, SU7H, SU8H, SU9H, and SU10H are bovine mastitis isolates from the Laboratorios Hipra S.A. strain collection. Strains SU1H, SU4H, SU5H, SU6H, $\mathrm{SU} 7 \mathrm{H}$, and $\mathrm{SU} 8 \mathrm{H}$ were isolated from clinical cases of bovine mastitis in Spain. Strain SU1H was selected as the vaccine strain based on its high ability to form biofilm in vitro. Strains SU2H, SU9H, and SU10H were isolated from clinical cases of bovine mastitis in the United Kingdom. Strain SU2H was selected as a challenge strain in a previous challenge model study (data not shown). Strain 0140J (ATCC-BAA-854; provided by the American Type Culture Collection, Manassas, VA) is a well-characterized bovine mastitis strain.

\section{Biofilm Formation and Inhibition Assays}

Bacterial inoculums for biofilm assays were prepared as follows: lyophilized cultures in glass vials were thawed, suspended with $1 \mathrm{~mL}$ of ultrapure sterile water, plated on Columbia III agar with $5 \%$ sheep blood (Becton Dickinson, Franklin Lakes, NJ), and incubated overnight at $37^{\circ} \mathrm{C}$. After confirmation of viability and purity, 3 single colonies were inoculated in $20 \mathrm{~mL}$ of tryptic soy broth (Becton Dickinson) containing 0.5\% yeast extract (Becton Dickinson; TSB+YE) and incubated at $37^{\circ} \mathrm{C}$ for $16 \mathrm{~h}$. The ability of $S$. uberis to form biofilm was evaluated using 96-well polystyrene plates (Thermo Fisher Scientific, Waltham, MA) as follows: 16-h cultures of SU1H, SU2H, SU4H, SU5H, SU6H, SU7H, SU8H, SU9H, SU10H, and 0140J were diluted 1:100 in TSB+YE, and $200 \mu \mathrm{L}$ of the suspensions was used to inoculate 96-well polystyrene plates. Fresh TSB+YE medium without bacterial culture was inoculated as a negative control, and cells were grown for $24 \mathrm{~h}$ at $37^{\circ} \mathrm{C}$. Then, planktonic suspensions were removed and wells were washed 3 times with PBS and dried for $1 \mathrm{~h}$ at $37^{\circ} \mathrm{C}$. Cells were heat-fixed and stained with a $0.5 \%$ (vol/vol) crystal violet solution (Merck, Darmstadt, Germany) for 10 min at room temperature. The stain was removed and the wells were washed 4 times with $300 \mu \mathrm{L}$ of PBS. Stained biofilms were diluted in $200 \mu \mathrm{L}$ of $96 \%$ ethanol and then incubated under orbital agitation for $2 \mathrm{~h}$. Finally, the optical density at $595 \mathrm{~nm}$ was measured using a microplate reader (Tecan Group Ltd., Männedorf, Switzerland). The experiment was conducted for $3 \mathrm{~d}$ using 8 wells in each plate for the culture of 1 strain. The optical density values for 24 wells were obtained for each isolate and used to determine the mean value.

For the biofilm inhibition assay, a 1:2,000 dilution of a vaccinated or unvaccinated sera and a 1:10 or 1:100 dilution of a lipoteichoic acid (LTA)-specific monoclonal antibody (Hycult Biotech Inc., Plymouth Meeting, PA) were added to 16-h SU1H cultures used to perform the biofilm formation assay. As a positive control, one 16-h SU1H culture was left without serum or mAb. Once the 96-well polystyrene plates were inoculated, the biofilm formation assay was performed as described above.

\section{Antigen Preparation}

The antigen fraction from $S$. uberis was obtained as follows: lyophilized cultures in glass vials of strain SU1H were thawed, suspended with $1 \mathrm{~mL}$ of ultrapure sterile water, diluted 1:200 on TSB+YE, and incubated 5 to $6 \mathrm{~h}$ at $37^{\circ} \mathrm{C}$ under stirring. Then, the bacterial suspension was diluted 1:100 in fresh TSB+YE medium and incubated at $37^{\circ} \mathrm{C}$ for $16 \mathrm{~h}$. After confirmation of viability and purity, overnight cultures were diluted 1:100 in TSB+YE and cultured in cell culture flasks (Nunc, Roskilde, Denmark) at $37^{\circ} \mathrm{C}$ in $5 \% \mathrm{CO}_{2}$ for $48 \mathrm{~h}$ in static conditions. Afterward, adhered biofilm-forming cells were harvested and suspended in deionized water and then autoclaved at $121^{\circ} \mathrm{C}$ for $45 \mathrm{~min}$ and centri- 
fuged at $14,000 \times g$ for $20 \mathrm{~min}$. Finally, the supernatant was recovered and stored at $4^{\circ} \mathrm{C}$ as the antigen fraction (BAC).

\section{Western Blotting}

Taking into account the extraction method of the antigen, only thermostable components were expected to remain structurally intact after the heat treatment. For this reason, the presence of LTA in the BAC antigen was assessed by Western blot analysis. Test antigen (10 $\mu \mathrm{L})$ and commercial LTA (50 $\mu \mathrm{g}$ of LTA) from Streptococcus pyogenes (ref. L3140; Sigma-Aldrich, St. Louis, $\mathrm{MO})$ as a positive control were mixed with sampling buffer (24 mM Tris-HCl, 1\% SDS, 5\% glycerol, $1.25 \%$ $\beta$-mercaptoethanol, $0.005 \%$ bromophenol blue) and resolved in 10\% Mini-Protean TGX precast gels (BioRad, Hercules, CA) using the Mini Protean III electrophoresis system (Bio-Rad). Then, gel was electrotransferred using the Mini Protean III electrophoresis system (Bio-Rad) onto a polyvinylidene difluoride membrane (Millipore Corp., Billerica, MA). Thereafter, the polyvinylidene difluoride membrane was blocked with $3 \%$ BSA in PBS containing $0.05 \%$ Tween-20 (PBST) overnight at room temperature. After washing with PBST, a 1:150 dilution of an LTA-specific monoclonal antibody (Hycult Biotech Inc.) in PBST was added to the membrane. After $1 \mathrm{~h}$ of incubation at $37^{\circ} \mathrm{C}$, the membrane was washed in PBST and incubated again with a 1:1,000 dilution of a polyclonal goat anti-mouse antibody (Jackson ImmunoResearch Laboratories Inc., Cambridgeshire, UK). Then, after washing 3 times with PBST, the membrane was incubated for $5 \mathrm{~min}$ in clarity Western ECL substrate (Bio-Rad) and imaged using the ChemiDoc MP imaging system (Bio-Rad).

\section{Cattle and Housing}

Twenty-five primigravid Holstein-Friesian dairy heifers in the last trimester of gestation were used in this study. After calving, these heifers were considered cows. The group size $(\mathrm{n}=12)$ was premised upon a $40 \%$ reduction in $S$. uberis bacterial count during the $21 \mathrm{~d}$ after challenge in vaccinates versus controls. Group sizes were determined using Ene 3.0 (Servei d'Estadistica Aplicada, Universitat Autònoma de Barcelona and the Biometric Department of GlaxoSmithKline, Bellaterra, Spain); estimated log values of bacterial count of cattle becoming infected with $S$. uberis in the vaccinated group and control group were 1.92 and 3.20, respectively, with a power of 0.80 and $\alpha$ of 0.05 . An additional heifer was added to the vaccinated group to ensure that 12 vaccinated heifers completed the study. Consequently,
13 heifers were included in the vaccinated group. Heifers were uniquely identified with paired, sequentially numbered ear tags, 1 in each ear. All heifers tested negative for bovine viral diarrhea virus persistent infection by reverse-transcription PCR (data not shown). Cattle were managed under the guidelines and approval of the Animal Care Committee of Laboratorios Hipra S.A. in compliance with Directive 2010/63/EU (European Union, 2010) on the protection of animals used for scientific purposes (granted on September 22, 2010). The experiment was conducted during a 5-mo period in winter and spring on an experimental farm (Gurb, Spain). During the experiment, the average low and high ambient temperature was 4 and $18^{\circ} \mathrm{C}$, respectively. Relative humidity ranged from $44 \%$ (average daily low) to $89 \%$ (average daily high). All heifers were housed together in a single pen with straw bedding and were the only heifers housed in that pen. New straw bedding was added approximately weekly. Heifers were fed with a TMR for cows in gestation and early lactation. Water was offered ad libitum throughout the study. After calving, calves were removed from their dam immediately, and all cows were milked twice daily at 0700 and $1700 \mathrm{~h}$.

\section{Milking Procedures}

Before milking, all teats of all cows were cleaned with a dry, single-use disposable paper towel to remove straw or other gross contaminant material. A chlorhexidine solution (OXA digluconate MAST P, Cygyc Industria Quimica S.A., Barcelona, Spain) was applied to each quarter, and after 20 to $30 \mathrm{~s}$ each teat was dried using another single-use disposable paper towel. Then, before milk appearance was assessed, all cows were forestripped. A California Mastitis Test paddle was used to assess milk appearance from each quarter. Afterward, quarter milk samples were aseptically collected for antibody analysis, bacterial count, and SCC. Milk samples for bacterial culture and antibody analysis were kept on ice (in the milking parlor) during sampling and then stored at $-20^{\circ} \mathrm{C}$. A second sample for SCC was collected following the same procedure described above but using nonsterile vials containing a broad-spectrum (bronopol and natamycin combination) preservative tablet (broad spectrum microtabs II; Advanced Instruments Inc., Norwood, MA). These samples were also kept on ice (in the milking parlor) during sampling, and after that they were stored at 4 to $6^{\circ} \mathrm{C}$ and shipped to a commercial laboratory (Associació Interprofessional Lletera de Catalunya, Cabrils, Spain) twice weekly for analysis by flow cytometry (Fossomatic FC; Foss Iberia S.A., Barcelona, Spain). Time delay between ud- 
der preparation and milking was approximately 90 to $120 \mathrm{~s}$ when assessment and sampling were performed (see "Sample and Data Collection"); if not, the time delay was approximately $60 \mathrm{~s}$. Milking units were attached just after udder preparation and were manually removed after milking. Afterward, all teats were dipped in iodine-based teat disinfectant. Milk weights were recorded from the in-line weigh jar, and the milking units were manually back-flushed with a dilute chlorhexidine digluconate solution (OXA MAST P, Cygyc Industria Quimica S.A.).

\section{Study Design}

All heifers were enrolled in the study between 71 and $77 \mathrm{~d}$ before the expected date of parturition. Distribution of these heifers into 2 groups was performed by sorting those heifers in function of the expected date of parturition. Two ranks of heifers were generated: rank 1, with the 13 heifers with the advanced state of gestation, and rank 2, with the remaining 12 heifers. Six heifers of each rank were randomly assigned to the control group, whereas the remaining heifers of each rank were assigned to the vaccinated group using computer software (Excel 2013, Microsoft Corp., Redmond, WA). Consequently, 13 heifers were assigned to the vaccinated group $(74.8 \pm 0.5 \mathrm{~d}$ before expected date of parturition) and the other 12 heifers were assigned to the control group $(74.7 \pm 0.6 \mathrm{~d}$ before expected date of parturition).

Fourteen days after enrollment in the study (between 57 and $63 \mathrm{~d}$ before the expected date of parturition), the vaccinated group $(\mathrm{n}=13)$ received the UBAC vaccine (2 mL; Laboratorios Hipra S.A., Amer, Spain), whereas the control group $(\mathrm{n}=12)$ received a PBS solution $(2 \mathrm{~mL})$. Both administrations were performed intramuscularly in the neck region. Thirty-nine days later, a second dose of UBAC vaccine or PBS was administered (between 18 and $24 \mathrm{~d}$ before the expected date of parturition).

Bacterial count and SCC of quarter milk samples were assessed 5, 2, and $1 \mathrm{~d}$ before challenge. After calving, each cow was challenged with $S$. uberis as detailed in the following section. After challenge, mastitis clinical signs, rectal temperature, milk yield, bacterial count, and SCC were monitored for $21 \mathrm{~d}$ as described below. Personnel involved in the animal experimental procedures, who gathered data on different parameters, were not aware of the treatment received by each individual heifer because heifers and treatments were randomized by a treatment dispenser who was not involved in gathering data.

\section{Intramammary Challenge}

Fourteen days after calving $(13.75 \pm 1.06 \mathrm{~d}$; d 0 of the study), each cow was challenged with $S$. uberis in the front right and rear right quarters. The averages \pm standard errors of the mean of milk yield were $24.7 \pm$ 1.14 and $26.8 \pm 1.42 \mathrm{~L} / \mathrm{d}$ for vaccinated and control cows, respectively. Inoculum was prepared as follows: lyophilized cultures in glass vials of the $\mathrm{SU} 2 \mathrm{H}$ strain were thawed and suspended with $1 \mathrm{~mL}$ of ultrapure sterile water. Then, they were plated on Columbia III agar with $5 \%$ sheep blood and incubated overnight at $37^{\circ} \mathrm{C}$. After confirmation of viability and purity, single colonies were seeded in tryptic soy agar (Becton Dickinson) containing $0.5 \%$ yeast extract (Becton Dickinson; $\mathrm{TSA}+\mathrm{YE}$ ) and incubated at $37^{\circ} \mathrm{C}$ for $24 \mathrm{~h}$. Bacterial growth was suspended in chilled PBS, harvested by centrifugation $\left(20 \mathrm{~min}\right.$ at $\left.5,000 \times g, 4^{\circ} \mathrm{C}\right)$, and adjusted to $100 \mathrm{cfu} / \mathrm{mL}$. Challenge doses were kept at $4^{\circ} \mathrm{C}$ in the laboratory. The next morning, the bacterial count result of the SUH2 suspension was checked $(108 \mathrm{cfu} / \mathrm{mL})$ and stored on ice in the milking parlor until infusion. Cattle were challenged as previously described (Oliver et al., 2004; Jackson et al., 2012; Kester et al., 2015) with some modifications. After the morning milking, 1 $\mathrm{mL}$ of the bacterial suspension was aseptically infused through a sterile plastic cannula into the front right and rear right quarters $(216 \mathrm{cfu} / \mathrm{cow})$. Finally, the teats were dipped with an iodine teat dip solution.

\section{Sample and Data Collection}

Visual examinations to assess cow demeanor were performed on each cow starting the day before the first vaccination ( $d-61$ of the study) and daily until the end of the study (d 21 of the study). Milk production per cow was recorded twice per day from calving until study completion. Mastitis clinical signs of each quarter and rectal temperatures were monitored on the mornings of $\mathrm{d} 5,2$, and 1 before challenge $(\mathrm{d}-5,-2$, and -1 of the study); twice per day from challenge to $7 \mathrm{~d}$ after challenge (d 0 to 7 of the study); and at the morning milking from 8 to $21 \mathrm{~d}$ after challenge (d 8 to 21 of the study). Milk samples for the bacterial and SCC analysis were individually collected from all quarters (infected or not) at the same monitoring times used for assessment of mastitis clinical signs. Blood samples for serological analysis were collected from each cow 60 and $21 \mathrm{~d}$ before parturition ( $\mathrm{d}-75$ and -36 of the study, respectively), the day of the challenge (d 0), and $21 \mathrm{~d}$ after challenge (d 21).

Mastitis clinical signs of all quarters were monitored using a composite score of visual abnormalities in milk 
and clinical evaluation of the mammary gland. Clinical scores of abnormalities in milk were performed by visual examination. One score was assigned to each quarter based on a visual 5 -point scale, where $0=$ normal milk; $1=$ presence of small clots or flakes $(<5 \mathrm{~mm}$ diameter) or slightly yellowish color but normal milk density (normal milk with small clots); $2=$ presence of clots $>5 \mathrm{~mm}$ diameter or yellowish color but normal or slightly affected milk density (normal milk with large clots); $3=$ presence of large clots ( $>10 \mathrm{~mm}$ diameter) or marked yellowish color with notable alteration of milk density (coagulated milk or transparent milk); 4 $=$ presence of large or small clots with clearly affected milk color and density; and $5=$ bloody milk. Clinical scores of mammary gland were performed by palpation and visual examination and were assigned to each quarter based on a 4 -point scale, where $0=$ normal appearance of quarter; 1 = pain on palpation, redness and swelling, or sclerosis of $<25 \%$ of the parenchyma; 2 $=$ pain on palpation, redness and swelling, or sclerosis from 25 to $50 \%$ of the parenchyma; $3=$ pain on palpation, redness and swelling, or sclerosis from 50 to $75 \%$ of the parenchyma; and $4=$ pain on palpation, redness and swelling, or sclerosis of $>75 \%$ of the parenchyma. Then, the composite score of mastitis clinical signs was performed per cow, considering the sum of the scores of milk assessment and mammary gland effects of the 2 challenged quarters per cows.

\section{Bacterial Count and SCC Analysis}

Quarter milk samples, collected for the bacteriological analysis, were thawed at $4^{\circ} \mathrm{C}$ for $12 \mathrm{~h}$. Quantitative bacteriological analysis was performed spreading $100 \mu \mathrm{L}$ of homogenized milk samples onto Columbia III agar with $5 \%$ sheep blood plates by means of the Spiral Plater Eddy Jet 2 (IUL Instruments, Barcelona, Spain). After $24 \pm 4 \mathrm{~h}$ of incubation at $37 \pm 2^{\circ} \mathrm{C}$, the identity of $S$. uberis was confirmed by the colony morphology (size, color), Gram stain, and oxidase and catalase reactivity. Colony-forming units per milliliter of each sample, compatible with S. uberis, were estimated using the Flash and Go colony counter reader and software (IUL Instruments). Negative samples (with no bacterial isolation) were confirmed again by bacterial culture of $250 \mu \mathrm{L}$ of homogenized milk samples onto Columbia III agar with $5 \%$ sheep blood plates. The determination of SCC was carried out at the referential laboratory, Associació Interprofessional Lletera de Catalunya, by flow cytometry (Fossomatic FC; Foss Iberia S.A.). These results were reported electronically via email attachment.

\section{Antibody Response}

Individual serum and milk samples were analyzed in duplicate for specific IgG2 antibodies against LTA by an indirect ELISA. Briefly, 96-well polystyrene plates were coated with commercial LTA from $S$. pyogenes (Sigma-Aldrich) by adding $50 \mu \mathrm{L}$ of LTA $(2.5 \mu \mathrm{g} / \mathrm{mL}$ in carbonate buffer) and incubating the plate for $1 \mathrm{~h}$ at $37^{\circ} \mathrm{C}$. The wells were washed with PBST and then blocked with $250 \mu \mathrm{L} /$ well of Stabilcoat (SurModics IVD Inc., Eden Prairie, MN) for $1 \mathrm{~h}$ at $37^{\circ} \mathrm{C}$. Wells were washed again, and $50 \mu \mathrm{L}$ of 100 -fold diluted serum or $50 \mu \mathrm{L}$ of whey milk was added to each well. A 100-fold dilution of a positive serum from a previously vaccinated cow was added to the plate as a positive control. This serum was obtained $57 \mathrm{~d}$ after the administration of 2 doses of the vaccine. A negative serum from a nonvaccinated heifer was also added to each plate as a negative control. Plates were incubated for $1 \mathrm{~h}$ at $37^{\circ} \mathrm{C}$. After washing, wells were incubated at $37^{\circ} \mathrm{C}$ for another hour with $50 \mu \mathrm{L}$ of monoclonal anti-bovine IgG2 antibody (ref. 9D8P; Thermo Fisher Scientific) at a 1:2,000 dilution in PBST. Plates were washed 3 times, and $50 \mu \mathrm{L}$ of 2,2'-azino-bis (3-ethylbenzothiazoline6-sulphonic acid; Sigma-Aldrich) was added. Reactions were stopped after $7 \mathrm{~min}$, and the optical density (OD) was read at $405 \mathrm{~nm}$. Antibody levels were expressed in relative index percentage (RIPC) using the following formula: $\mathrm{RIPC}=(\mathrm{OD}$ sample $-\mathrm{OD}$ negative control $) /$ (OD positive control - OD negative control) $\times 100$.

\section{Calculations and Statistical Analysis}

Total mastitis clinical signs per cow were calculated as the sum of the scoring of mastitis clinical signs observed in both challenged quarters per time point assessment. The comparison between the vaccinated and control groups was conducted in all time point assessments using the Wilcoxon rank sum test within PROC NPAR1WAY of SAS (SAS Institute Inc., Cary, $\mathrm{NC}$ ); therefore, data were not parametric. The area under the curve (AUC) of mastitis clinical signs was calculated for each cow using the data gathered from d 0 to d 21; 1 value per cow was obtained. The AUC data of the vaccinated group were compared with those of the control group using a $t$-test within the MIXED procedure of SAS.

Milk samples collected to assess the bacterial count and SCC were analyzed individually at a quarter level. The statistical analysis of bacterial count and SCC was performed using ANOVA in MIXED and GLIMMIX procedures of SAS version 9.4 (SAS Institute Inc.). Quarter values were log-transformed to satisfy normal- 
ity assumptions. Treatment, sampling time, the quadratic effect of sampling time, and treatment $\times$ sampling time interactions were included as fixed effects. Random effects were considered, including cow-specific random intercept and quarter within cow-specific random intercept, slope, and quadratic sampling time trends. The evolution of bacterial count and SCC had a nonlinear pattern. To allow the fitting of a quadratic model, the analysis was conducted considering times from d 5 onward. Geometric means were estimated for each time period. The data from the bacterial count and SCC of each sampling time per quarter were also used to compare vaccinated and control groups to assess the incidence (percentage) of quarters with no bacterial isolation and SCC $<200,000$ cells $/ \mathrm{mL}$ from the afternoon of $\mathrm{d} 0$ to $\mathrm{d} 21$ (per day) using the logistic regression in PROC GLIMMIX of SAS version 9.4.

Milk production recorded from 7 to $1 \mathrm{~d}$ before challenge was used to calculate the baseline of milk production of each cow. Then, the percentage of milk production per day was calculated considering the production per day divided by the baseline of each cow. These data per day were analyzed using PROC MIXED of SAS. The model included the fixed effects of treatment, sampling time, and treatment $\times$ sampling time interaction and the random effect of each cow within treatment. Compound symmetry was selected as the variance-covariance matrix structure for the increase in milk production data based on best fit according to Schwarz's Bayesian information criterion.

The normal rectal temperatures of cows is considered to range from 38.5 to $39.5^{\circ} \mathrm{C}$ (Constable et al., 2016). Rectal temperature data were converted into binomial, normal values $\left(\leq 39.5^{\circ} \mathrm{C}\right)$ or abnormal values $\left(>39.5^{\circ} \mathrm{C}\right)$. The analysis of this data was performed using the chisquared test within PROC FREQ in SAS per day.

Data on biofilm formation and inhibition were compared using Student's $t$-test in SAS. Data are shown as mean \pm standard deviation. Serum and milk ELISA data within the vaccinated and control groups were compared using Student's t-test in SAS. Results are shown as RIPC mean \pm standard error of the mean. All values reported are least squares means. Significance was declared at $P \leq 0.05$.

\section{RESULTS}

\section{Vaccine Strain Selection Based on Biofilm Formation Ability}

Biofilm formation in TSB $+\mathrm{YE}$ was confirmed in 7 out of 10 S. uberis isolates (SU1H, SU2H, SU4H, SU5H, SU6H, SU8H, and SU9H), as they showed a significantly higher mean optical density compared with the noninoculated wells $(P<0.05)$ in the microplate assay (Figure 1). Furthermore, strain SU1H was selected as the vaccine strain because it described the highest biofilm formation ability, although no significant differences were observed with SU4H and SU6H strains.

\section{Antigen Characterization}

Western blot analysis results demonstrated that the BAC antigen contained LTA, as a band was detected with an LTA-specific monoclonal antibody. In addition, serum and milk samples from vaccinated heifers were analyzed by ELISA, demonstrating the immunogenicity of the LTA contained in the BAC antigen. In addition, serum and milk samples from vaccinated heifers were analyzed by ELISA, demonstrating the immunogenicity of the LTA contained in the BAC antigen (Figure 5).

\section{Mastitis Clinical Signs}

Before challenge, no cow had mastitis clinical signs or alterations in behavior. After challenge, all cows developed clinical mastitis in the challenged quarters. No signs of clinical mastitis or S. uberis isolation were detected in the nonchallenged quarters during the study. As shown in Figure 2A, both groups showed similar increases of clinical signs in the challenged quarters, achieving the highest score value $3 \mathrm{~d}$ after experimental infection. From d 4 after challenge until the end of the study (d 21), vaccinated cows showed a significant $(P<$ $0.05)$ reduction in mastitis clinical signs on d 6 a.m., d 7 p.m., d 9 a.m., d 10 a.m., d 11 a.m., d 16 a.m., and d 17 a.m. compared with control cows. The AUC analysis demonstrated that vaccinated cows had a significant reduction in mastitis clinical signs compared with control cows from d 0 to d $21(2.85 \pm 0.22$ vs. $3.5 \pm 0.17$; $P<0.05)$.

\section{Bacterial Count and SCC}

Milk samples from nonchallenged quarters were bacteriologically negative to $S$. uberis and other mastitis pathogens throughout the study. Concerning challenged quarters, milk samples collected on $\mathrm{d}-5, \mathrm{~d}-2$, and $\mathrm{d}$ -1 were negative for bacterial culture for $S$. uberis and other mastitis pathogens. After experimental infection, these challenged quarters had a peak of bacterial count on d 2 a.m. and d 3 a.m. in vaccinated and control groups, respectively, as shown in Figure 2B. After that, bacterial count was reduced in both groups until a second peak was observed $6 \mathrm{~d}$ after challenge. Vaccinated cows had a significant $(P<0.05)$ reduction in bacterial count from d 15 to d 21 compared with control cows. 
In terms of SCC, all cows had SCC $<200,000$ cells/ $\mathrm{mL}$ on $\mathrm{d}-5, \mathrm{~d}-2, \mathrm{~d}-1$, and $\mathrm{d} 0$. After experimental infection, nonchallenged quarters had $<200,000$ cells/ $\mathrm{mL}$ throughout the entire study. Considering the challenged quarters, the experimental infection increased the mean SCC, although no differences were found between groups during the entire study (Figure 2C). With regard to the percentage of challenged quarters with no bacterial isolation and SCC $<200,000$ cells/mL per day during the study, the vaccinated group described a significantly $(P<0.05)$ greater percentage on d 19 (71.1 vs. $16.7 \%)$, d 20 (70.2 vs. $10.8 \%)$, and d 21 (66.0 vs. $5.9 \%$ ) compared with the control group.

\section{Rectal Temperature and Milk Production}

After challenge, an increased rectal temperature was observed in all cows. The average temperature reached a peak of $40.1 \pm 0.27^{\circ} \mathrm{C}$ and $40.32 \pm 0.30^{\circ} \mathrm{C}$ at $\mathrm{d} 2$ a.m. in the vaccinated and control groups, respectively. However, regarding the percentage of cows with rectal temperature $>39.5^{\circ} \mathrm{C}$, no differences between groups were recorded during the first $3 \mathrm{~d}$ after challenge (Figure 3 ). After that, the vaccinated group had a significantly
$(P<0.05)$ lower percentage of cows $>39.5^{\circ} \mathrm{C}$ compared with the control group on d 4 a.m., d 5 a.m., d 5 p.m., and $\mathrm{d} 7 \mathrm{p.m}$.

No differences were found in milk production of cows between groups before challenge. The averages \pm standard errors of the mean of milk yield were $24.7 \pm$ $1.14 \mathrm{~L}$ for the vaccinated group and $26.8 \pm 1.42 \mathrm{~L}$ for the control group. After challenge, milk production decreased in all cows. In vaccinated cows, the mean difference in milk production at baseline decreased, reaching the negative peak at $\mathrm{d} 2$. After that, milk production increased and reached similar values of baseline production on d 8 postchallenge (Figure 4). On the other hand, control cows showed a decrease until d 5, and baseline production was attained on $\mathrm{d} 18$. Vaccinated cows showed significantly $(P<0.05)$ greater values in milk yields compared with the control group on $\mathrm{d} 9, \mathrm{~d}$ 13, d 14, d 15, d 17, and d 21.

\section{Antibody Response}

The ELISA results showed that there were no significant differences between groups in the level of serum IgG2 antibodies against LTA before vaccination (d

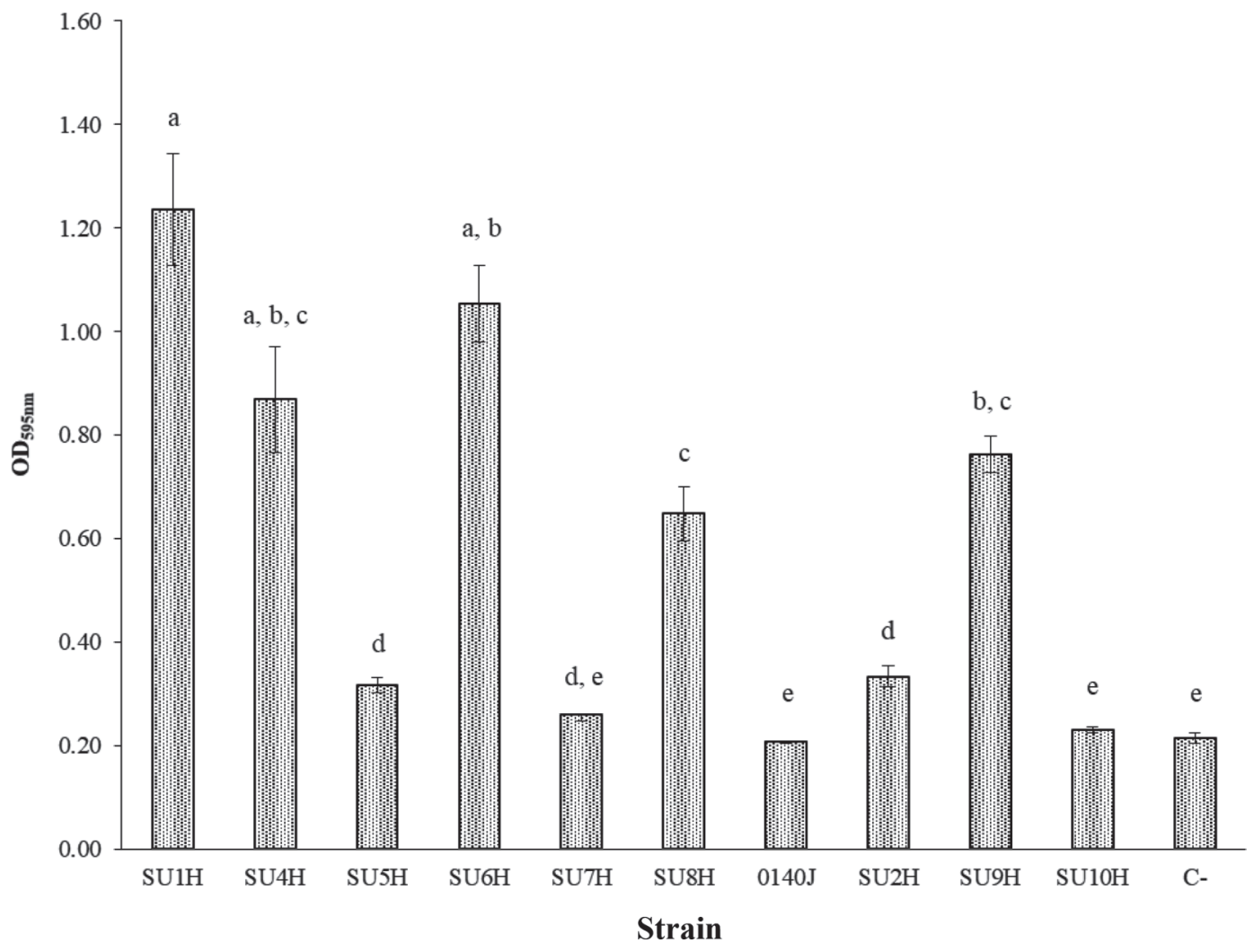

Figure 1. Biofilm formation of Streptococcus uberis strains. Biofilm formation was tested in tryptic soy broth $+0.5 \%$ yeast extract. Uninoculated media was used as a negative control $(\mathrm{C}-)$. Bars represent the average sample optical density at $595 \mathrm{~nm}\left(\mathrm{OD}_{595 \mathrm{~nm}}\right)$ after $24 \mathrm{~h}$ of culture at $37^{\circ} \mathrm{C}$ and SD. The assay was conducted on 3 different days, and for each assay the result was based on the average of 8 wells. Different letters $(\mathrm{a}-\mathrm{e})$ indicate significant differences $(P<0.05)$ between strains. 
$\mathbf{A}$

$\bullet \square \cdot$ Vaccinated Control
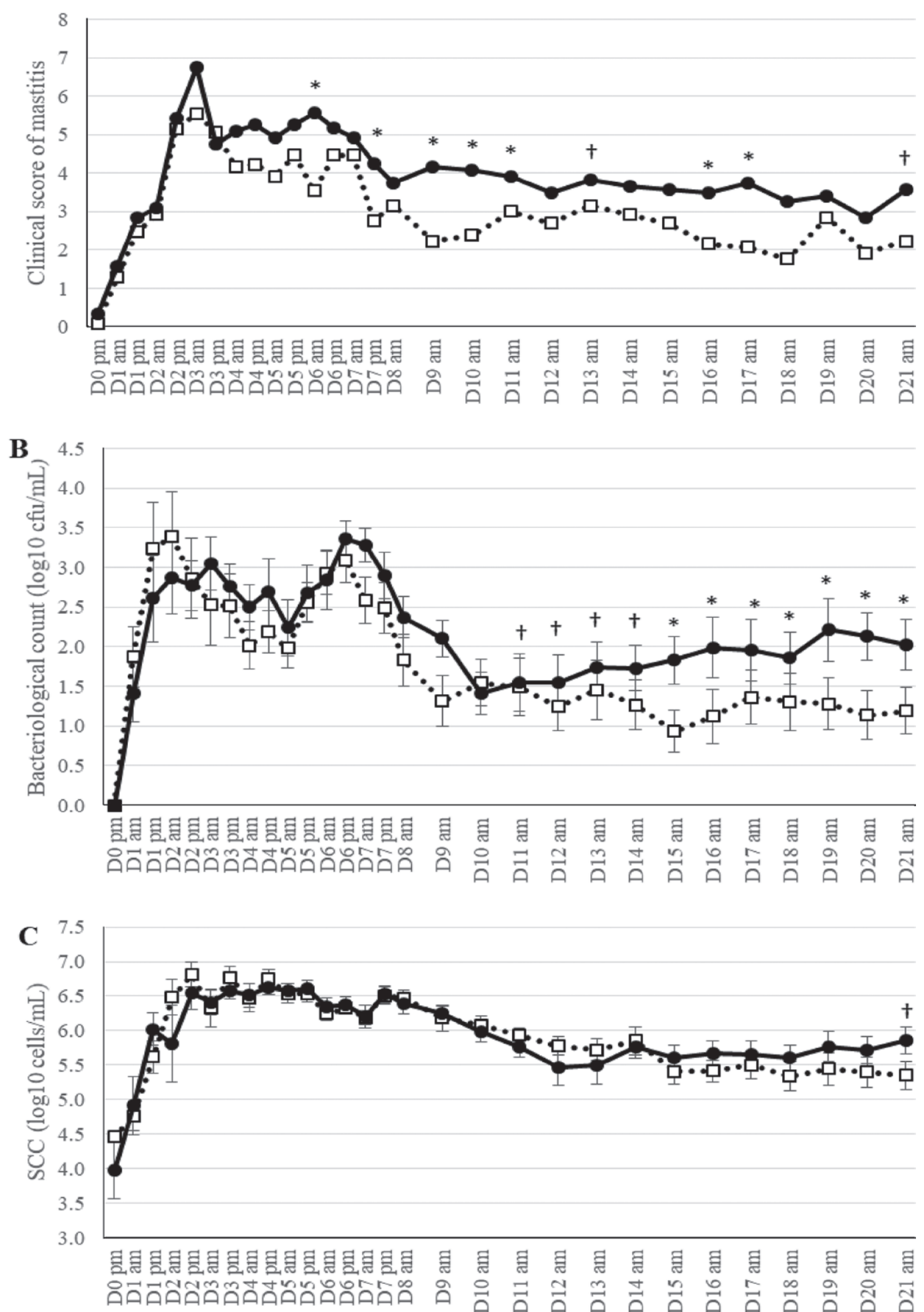

Days after challenge

Figure 2. (A) Daily average of clinical mastitis scores of vaccinated and control groups from challenge to $21 \mathrm{~d}$ after experimental infection. (B) Geometric means \pm SEM of daily bacterial count $(\log \mathrm{cfu} / \mathrm{mL})$ of vaccinated and control groups from challenge to $21 \mathrm{~d}$ after experimental infection. (C) Geometric means \pm SEM of daily SCC $\left(\log _{10}\right.$ cells $\left./ \mathrm{mL}\right)$ of vaccinated and control groups from challenge to $21 \mathrm{~d}$ after experimental infection. *Significant differences $(P<0.05)$ between groups; trends $(0.05<P \leq 0.10)$ between groups. 
$-75)$. In response to the first dose of vaccine, the vaccinated group had significantly increased $(P<0.05)$ IgG2 levels against LTA on day -36 compared with the control group, demonstrating the immunogenic activity of LTA contained in the BAC antigen (Figure $5 \mathrm{~A})$. Differences between groups were also observed after the second dose of vaccine on $\mathrm{d} 0$ and after the experimental infection on d 21, where higher anti-LTA antibody levels were observed in the vaccinated group compared with the control group $(P<0.05)$. Regarding the antibody response in milk, whey IgG2 levels against LTA in the vaccinated group were higher than those in the control group after the second dose of vaccine on d $0(P<0.05$; Figure 5B). On the other hand, a significant increase in the antibody levels against LTA in serum and milk was found in the control group on d 21 compared with d 0 , indicating that the experimental IMI induced an antibody response in control cows.

\section{Biofilm Formation Inhibition Assay}

The putative effect on biofilm formation of antibodies generated through vaccination was later evaluated in vitro. First, it was confirmed that the addition of serum $(1: 2,000)$ from a vaccinated or unvaccinated cow or an mAb against LTA to an S. uberis $\mathrm{SU} 1 \mathrm{H}$ culture did not result in any significant difference in their growth $\left(\mathrm{OD}_{550 \mathrm{~nm}}\right)$ at the end of the incubation period compared with an S. uberis SU1H culture without serum or mAb (Figure 6A and Figure 7A, respectively). After that, planktonic cells were removed and cells adhering to the bottom of the microplate were stained. Results showed that wells previously incubated with serum from a vaccinated cow exhibited lower biofilm formation (lower $\left.\mathrm{OD}_{595 \mathrm{~nm}}\right)$ than the wells incubated with a serum from an unvaccinated cow or without serum $(P<0.05$; Figure 6B). Moreover, wells incubated with a 1:10 dilution of a $\mathrm{mAb}$ against LTA showed lower biofilm formation $(P<$ $0.05)$ than the wells incubated with a 1:100 dilution of $\mathrm{mAb}$ against LTA or without $\mathrm{mAb}$ (Figure 7B). These results indicate that sera and LTA $\mathrm{mAb}$ did not have any effect in the total growth (planktonic and biofilm) reached at the end of the incubation. Nevertheless, serum from a vaccinated cow and an $\mathrm{mAb}$ against LTA were able to inhibit the adhesion and biofilm formation of $S$. uberis in the bottom of the wells.

\section{DISCUSSION}

In this study, the efficacy of a novel $S$. uberis subunit vaccine was evaluated in dairy cows. Cows were vaccinated with a total of 2 doses of the vaccine before calving and challenged with a heterologous strain of $S$. uberis after calving. The vaccine strain $\mathrm{SU} 1 \mathrm{H}$ was selected due to its high in vitro biofilm-producing ability, and the vaccine antigen (BAC) was obtained from SU1H biofilm-forming cells and analyzed.

Due to the method of extraction, we believed that only thermostable components could remain functional in the BAC antigen. Therefore, thinking that nonprotein components from the gram-positive bacterial surface could play an important role in the pathogenesis of bacterial infections, we evaluated and confirmed the presence of LTA in the final antigen with an mAb. Sev-

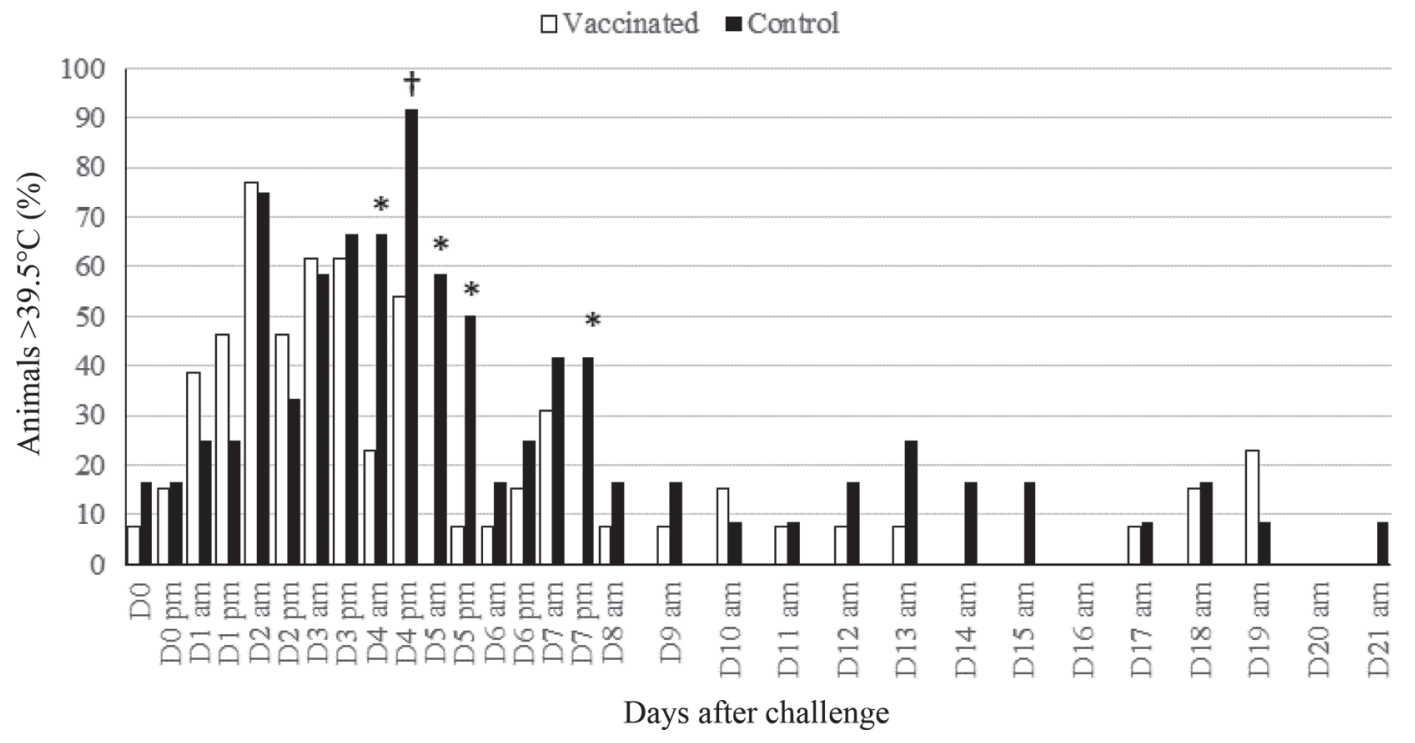

Figure 3. Percentage of cows $>39.5^{\circ} \mathrm{C}$ of vaccinated and control groups from challenge to $21 \mathrm{~d}$ after experimental infection. ${ }^{*}$ Significant differences $(P<0.05)$ between groups; †trends $(0.05<P \leq 0.10)$ between groups. 
eral authors have previously discussed the relevance of LTA in pathogenesis. Weidenmaier and Peschel (2008) stated that LTA seems to be indispensable for cell viability and important in cell division and in binding cell wall proteins. Moreover, Gross et al. (2001) and Fabretti et al. (2006) demonstrated that LTA mutants of Staphylococcus aureus and Enterococcus faecalis, respectively, exhibit a reduced primary adhesion that leads to reduced biofilm formation ability in vitro compared with wild type strains. In the same line, our study demonstrated that a specific mAb against LTA was able to reduce $(P<0.05)$ the biofilm-formation ability of $S$. uberis in vitro, suggesting, to our knowledge for the first time, that LTA could be involved in the $S$. uberis biofilm formation in vitro. Therefore, concerning bovine mastitis, the role of LTA during an IMI could be related to the binding of the bacteria to the host epithelial cells in a primary stage, as stated by Czabańska et al. (2012), followed by a step of biofilm formation as a strategy of colonization and persistence in the mammary gland (Melchior et al., 2006).

After challenge, all vaccinated and control cows developed clinical mastitis, indicating that the challenge was successful. However, the vaccinated group showed a significant reduction in the severity of the mastitis clinical signs in the challenged quarters. Furthermore, vaccinated cows showed a significant reduction in the bacterial count in milk of challenged quarters several days after the experimental infection. Regarding SCC, the vaccine did not induce changes in the SCC observed after experimental infection in the challenged quarters compared with the control group. However, when analyzing these data together with the bacterial data, the number of challenged quarters with no bacterial isolation and SCC $<200,000$ cells/mL becomes significantly $(P<0.05)$ higher in the vaccinated group than in the control group at the end of the study. Rectal temperatures and milk production data were in accordance to those observed for bacterial count. Both groups showed similar results during the $3 \mathrm{~d}$ after challenge, but after that an improvement was noticed in the vaccinated group compared with the control group. With regard to rectal temperature, the percentage of cows $>39.5^{\circ} \mathrm{C}$ was significantly greater on d 4 a.m., d 5 a.m., d 5 p.m., and $\mathrm{d} 7$ p.m. in the control group than in the vaccinated group. In terms of cow milk production, a decrease was observed in both groups during the first days after challenge. However, control cows recovered the milk production baseline level $18 \mathrm{~d}$ after challenge, whereas vaccinated cows required only $8 \mathrm{~d}$, decreasing milk losses associated with the IMI. Despite these differences, we cannot be sure that milk production levels of the vaccinated group reached the expected milk yield of noninfected cows because a sentinel group was not included in the study.

Data presented in this study demonstrated that vaccination with $\mathrm{BAC}$ antigen reduced the clinical symptoms of acute $S$. uberis mastitis caused by ex-

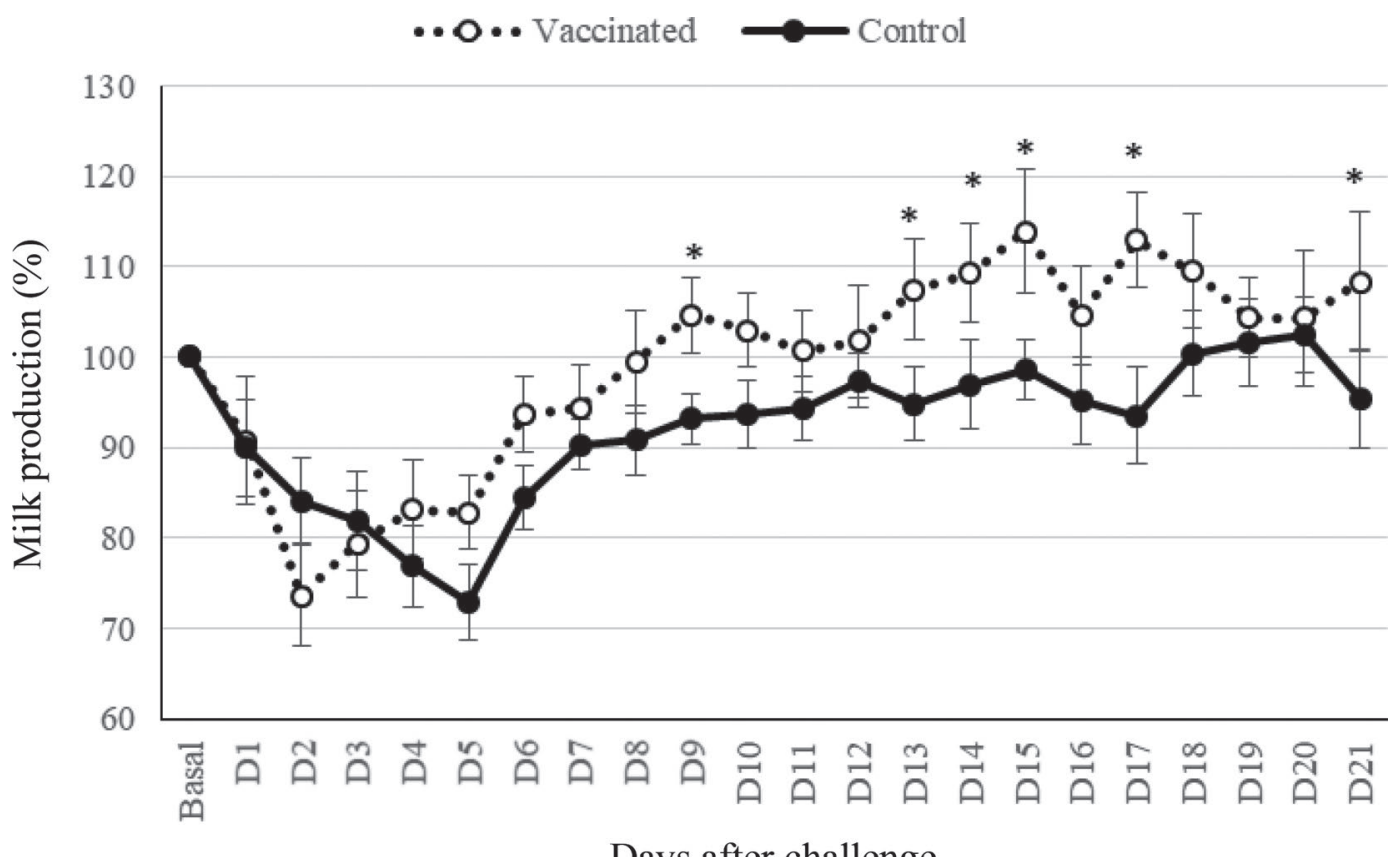

Figure 4. Daily average percentage of milk yield (L) versus prechallenge of vaccinated and control groups from challenge to $21 \mathrm{~d}$ after experimental infection. ${ }^{*}$ Significant differences $(P<0.05)$ between groups. Error bars indicate \pm SEM. 
perimental challenge, possibly associated with lower bacterial concentrations in vaccinated cows. Moreover, this study suggested faster recovery of vaccinated cows after an experimental IMI: the percentage of challenged quarters with no bacterial isolation and SCC $<200,000$ cells/mL at the end of the study was significantly higher in the vaccinated group, and vaccinated animals recovered their baseline level of milk production earlier compared with the control group. Nevertheless, given the relatively short duration of our trial, it cannot be ensured that the infection was completely cleared in any of the challenged quarters.

Concerning the immune response, our study demonstrated that vaccination with $\mathrm{BAC}$ antigen can induce high antibody levels against LTA in serum and milk. Moreover, the activity of these antibodies was tested in vitro, and results showed their ability to reduce biofilm formation in a 96-well microtiter plate. Therefore, according to this result, we hypothesized that protection observed in the present study may be associated with
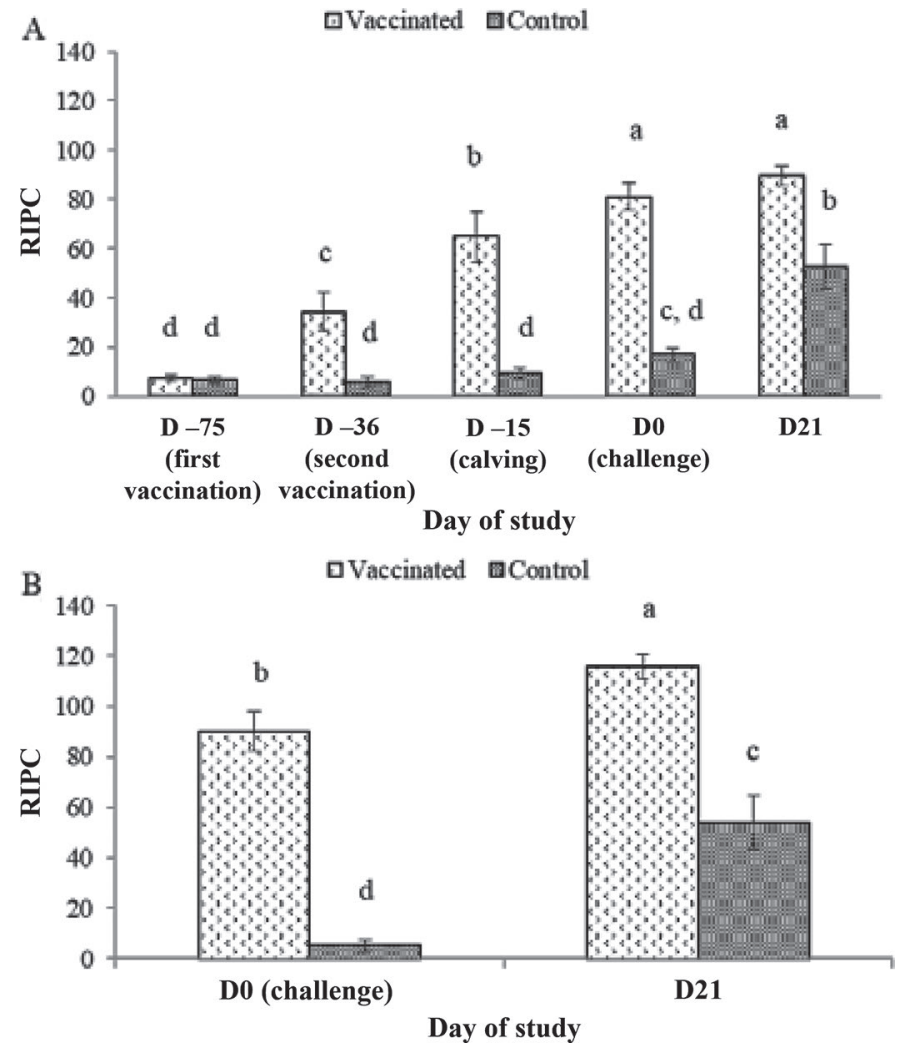

Figure 5. (A) Immunoglobulin G2 responses in sera samples from vaccinated and control heifers measured by indirect ELISA. The first and second doses of the vaccine were given on $\mathrm{d}-75$ and -36 , respectively. (B) Immunoglobulin G2 responses in milk samples from vaccinated and control cows measured by an indirect ELISA. Data are shown as the mean of the relative index percentage (RIPC) \pm SEM. Different letters $(\mathrm{a}-\mathrm{d})$ indicate significant differences $(P<0.05)$ between groups.

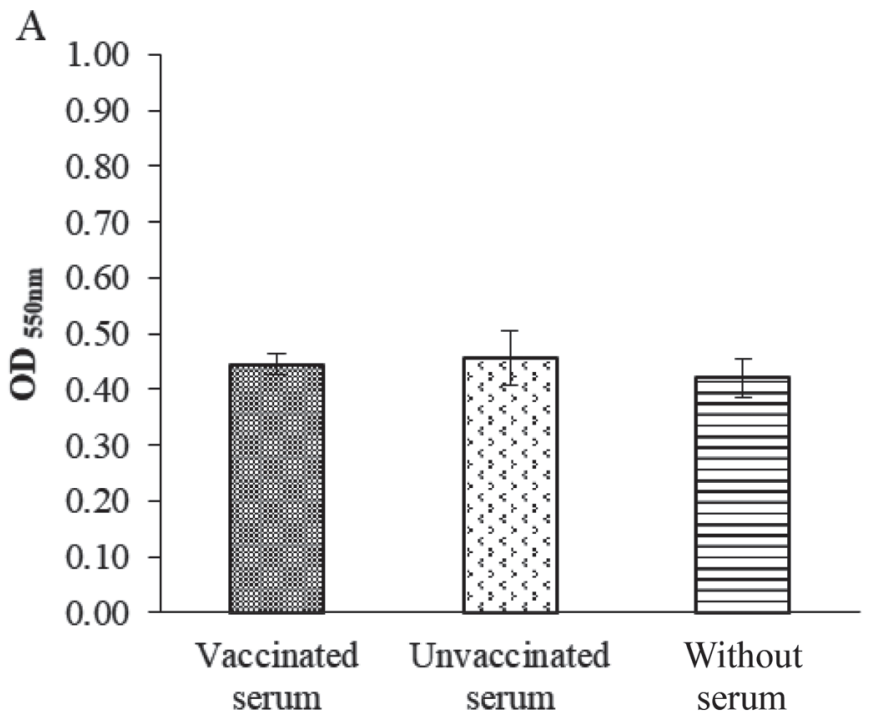

B

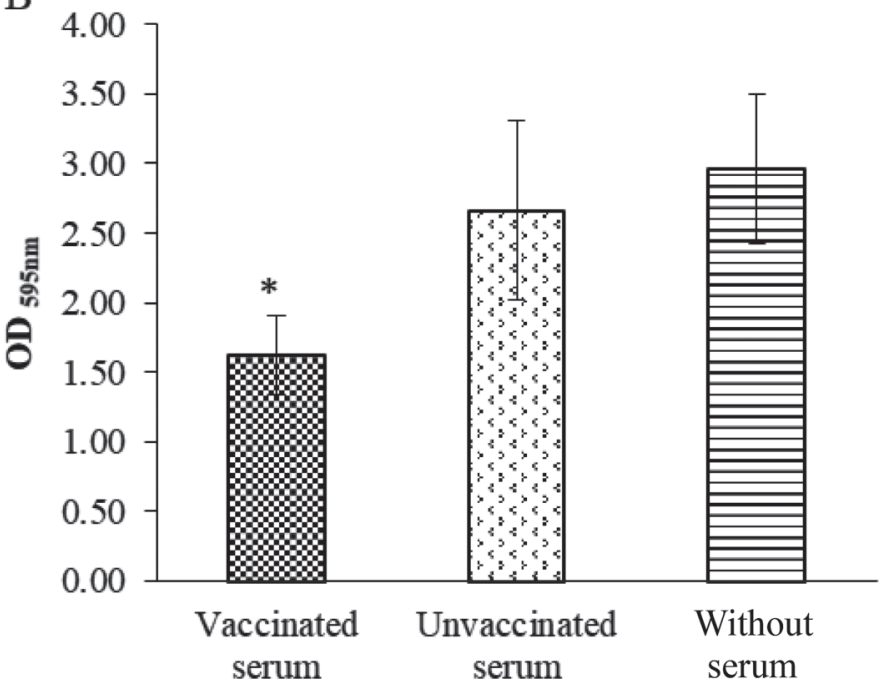

Figure 6. In vitro inhibition of biofilm formation. (A) Growth of Streptococcus uberis $\mathrm{SU1H}$ in tryptic soy broth $+0.5 \%$ yeast extract in the presence of a 1:2,000 dilution of vaccinated and unvaccinated serum and without serum. Bars represent the average optical density at $550 \mathrm{~nm}\left(\mathrm{OD}_{550 \mathrm{~nm}}\right)$ after $24 \mathrm{~h}$ of culture at $37^{\circ} \mathrm{C}$ and $\mathrm{SD}$. (B) Biofilm formation of $S$. uberis SU1H cultures in the presence of vaccinated and unvaccinated serum and without serum. Bars represent the average sample $\mathrm{OD}_{595 \mathrm{~mm}}$ after $24 \mathrm{~h}$ of culture at $37^{\circ} \mathrm{C}$ and $\mathrm{SD}$. The assay was conducted on 3 different days, and for each assay the result was based on the average of 8 wells. Significant reductions in in vitro biofilm formation are shown $(* P<0.05)$.

the induction of specific antibodies against $S$. uberis LTA. The presence of these antibodies in milk, when an IMI occurs, could interfere with the binding of the bacteria to the host epithelial cells, as suggested by Czabańska et al. (2012), preventing the subsequent biofilm formation. This could lead to a reduced S. uberis colonization rate of the mammary gland, which has been suggested as the mechanism of protection in other 
experimental vaccines (Finch, et al., 1994, 1997; Leigh et al., 1999), and a decrease in the persistence of the infection. Moreover, the reduction of bacterial counts in milk of vaccinated cows may also be due to the fact that milk IgG2 antibodies against BAC antigen could opsonize bacterial cells, favoring phagocytosis and clearance by polymorphonuclear neutrophils (Rainard and Riollet, 2003). However, that other components present in the BAC antigen, apart from LTA, could

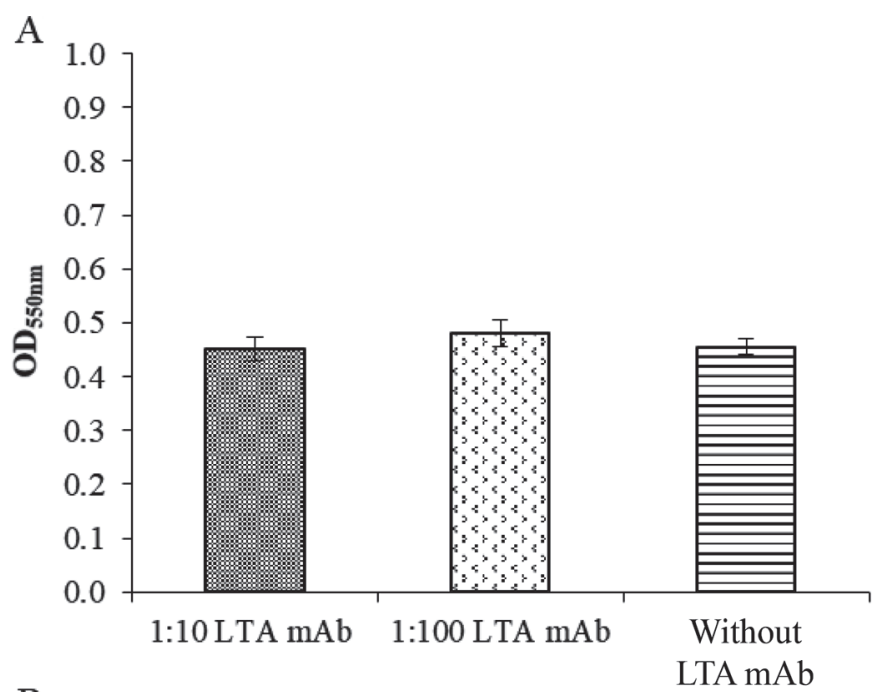

B

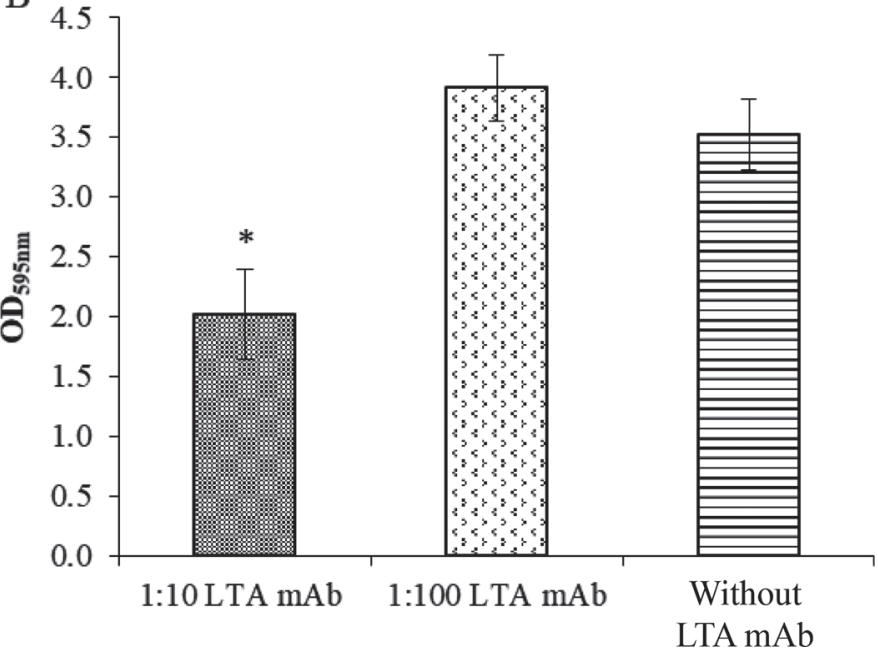

Figure 7. In vitro inhibition of biofilm formation. (A) Growth of Streptococcus uberis $\mathrm{SU} 1 \mathrm{H}$ in tryptic soy broth $+0.5 \%$ yeast extract in the presence of 1:10 and 1:100 dilution of an a monoclonal antibody $(\mathrm{mAb})$ against lipoteichoic acid (LTA) or without $\mathrm{mAb}$. Bars represent the average optical density at $550 \mathrm{~nm}\left(\mathrm{OD}_{550 \mathrm{~nm}}\right)$ after $24 \mathrm{~h}$ of culture at $37^{\circ} \mathrm{C}$ and SD. (B) Biofilm formation of S. uberis SU1H cultures in the presence of 1:10 and 1:100 dilution of an $\mathrm{mAb}$ against LTA or without $\mathrm{mAb}$. Bars represent the average sample $\mathrm{OD}_{595 \mathrm{~nm}}$ after $24 \mathrm{~h}$ of culture at $37^{\circ} \mathrm{C}$ and SD. The assay was conducted on 3 different days, and for each assay the result was based on the average of 8 wells. Significant reductions in in vitro biofilm formation are shown $\left({ }^{*} P<0.05\right)$. have a key role in the final outcome of the vaccine efficacy should not be ruled out.

There are only a few studies in which an experimental $S$. uberis mastitis vaccine has shown some protection upon challenge by heterologous IMI. Finch et al. (1997) tested 2 immunization plans: (1) a subcutaneous prime with a live $S$. uberis, followed by an intramammary booster with a soluble bacterial extract (2 control cows and 3 vaccinated cows), and (2) 2 subcutaneous vaccinations of live $S$. uberis (2 control cows and 4 vaccinated cows). A different approach was tested by Leigh et al. (1999), who used 2 subcutaneous immunizations with a concentrated culture of supernatant containing S. uberis plasminogen activator (PauA; 1 control cow and 4 vaccinated cows). In these studies, only limited efficacy in the reduction of the bacterial count in milk (Finch et al., 1997; Leigh et al., 1999) and SCC (Leigh et al., 1999) was observed after challenge. However, these studies used a smaller number of cows, and neither of them reported any statistical analysis supporting the results. In contrast, to our knowledge, this is the first time that a study showed statistically significant differences in mastitis clinical signs, bacterial count, temperature, and milk production, suggesting that vaccination enhanced cows' recovery from clinical mastitis after an acute infection with an heterologous strain.

In conclusion, the results presented in this study demonstrated that intramuscular immunization of dairy heifers with UBAC vaccine during the precalving period reduced the severity of clinical mastitis following experimental challenge of S. uberis. Even so, further studies are needed to assess vaccine efficacy under field conditions.

\section{ACKNOWLEDGMENTS}

We thank Laura Badia, Cristina Solà, and Judit Moreno (Laboratorios Hipra S.A., Amer, Spain) for their excellent assistance in the bacteriological and immunological analysis and Xavier Madeo (Laboratorios Hipra S.A.) for his essential technical assistance in the animal experimental phase.

\section{REFERENCES}

Archer, S. C., A. J. Bradley, S. Cooper, P. L. Davies, and M. J. Green. 2017. Prediction of Streptococcus uberis clinical mastitis risk using matrix-assisted laser desorption ionization time of flight mass spectrometry (MALDI-TOF MS) in dairy herds. Prev. Vet. Med. 144:1-6. https://doi.org/10.1016/j.prevetmed.2017.05.015.

Constable, P. D., K. W. Hinchcliff, S. H. Done, and W. Gruenberg. 2016. Clinical examination and making a diagnosis. Page 15 in Veterinary Medicine: A Textbook of the Diseases of Cattle, Horses, Sheep, Pigs and Goats. 11th ed. Elsevier Ltd., St. Louis, MO. 
Crowley, R. C., J. A. Leigh, P. N. Ward, H. M. Lappin-Scott, and L. D. Bowler. 2011. Differential protein expression in Streptococcus uberis under planktonic and biofilm growth conditions. Appl. Environ. Microbiol. 77:382-384. https://doi.org/10.1128/AEM.01099 -10 .

Czabańska, A., O. Neiwert, B. Lindner, J. A. Leigh, O. Holst, and K. A. Duda. 2012. Structural analysis of the lipoteichoic acids isolated from bovine mastitis Streptococcus uberis 233, Streptococcus dysgalactiae 2023 and Streptococcus agalactiae 0250. Carbohydr. Res. 361:200-205. https://doi.org/10.1016/j.carres.2012.09.007.

Davies, P. L., J. A. Leigh, A. J. Bradley, S. C. Archer, R. D. Emes, and M. J. Green. 2016. Molecular epidemiology of Streptococcus uberis clinical mastitis in dairy herds: Strain heterogeneity and transmission. J. Clin. Microbiol. 54:68-74. https://doi.org/10.1128/JCM .01583-15.

European Union. 2010. Directive 2010/63/EU of the European Parliament and of the Council of the European Union, of 22 September 2010. On the protection of animals used for scientific purposes. Official Journal of the European Union. L 276/33-79.

Fabretti, F. C. Theilacker, L. Baldassarri, Z. Kaczynski, A. Kropec, O. Holst, and J. Huebner. 2006. Alanine esters of enterococcal lipoteichoic acid play a role in biofilm formation and resistance to antimicrobial peptides. Infect. Immun. 74:4164-4171.

Finch, J. M., A. W. Hill, T. R. Field, and J. A. Leigh. 1994. Local vaccination with killed Streptococcus uberis protects the bovine mammary gland against experimental intramammary challenge with the homologous strain. Infect. Immun. 62:3599-3603.

Finch, J. M., A. Winter, A. W. Walton, and J. A. Leigh. 1997. Further studies on the efficacy of a live vaccine against mastitis caused by Streptococcus uberis. Vaccine 15:1138-1143.

Gross, M., S. E. Cramton, F. Götz, and A. Peschel. 2001. Key role of teichoic acid net charge in Staphylococcus aureus colonization of artificial surfaces. Infect. Immun. 69:3423-3426. https://doi.org/ 10.1128/IAI.69.5.3423-3426.2001.

Hogan, J. S., and K. L. Smith. 1997. Occurrence of clinical and subclinical environmental streptococcal mastitis. Pages 59-75 in Proceedings of the Symposium on Udder Health Management for Environmental Streptococci. National Mastitis Council, Arlington, VA.

Jackson, K. A., S. C. Nickerson, F. M. Kautz, and D. J. Hurley. 2012. Technical note: Development of a challenge model for Streptococcus uberis mastitis in dairy heifers. J. Dairy Sci. 95:7210-7213. https://doi.org/10.3168/jds.2012-5782.

Kester, H. J., D. E. Sorter, and J. S. Hogan. 2015. Activity and milk compositional changes following experimentally induced Streptococcus uberis bovine mastitis. J. Dairy Sci. 98:999-1004. https:// doi.org/10.3168/jds.2014-8576.

Leigh, J. A. 1999. A permanent barrier to the control of bovine mastitis? Vet. J. 157:225-238.
Leigh, J. A., J. M. Finch, T. R. Field, N. C. Real, A. Winter, A. W. Walton, and S. M. Hodgkinson. 1999. Vaccination with the plasminogen activator from Streptococcus uberis induces an inhibitory response and protects against experimental infection in the dairy cow. Vaccine 17:851-857. https://doi.org/10.1016/S0264 -410X(98)00270-9.

McDougall, S., D. G. Arthur, M. A. Bryan, J. J. Vermunt, and A. M. Weir. 2007. Clinical and bacteriological response to treatment of clinical mastitis with one of three intramammary antibiotics. N. Z Vet. J. 55:161-170. https://doi.org/10.1080/00480169.2007.36762.

Melchior, M. B.. H. Vaarkamp, and J. Fink-Gremmels. 2006. Biofilms: A role in recurrent mastitis infections? Vet. J. 171:398-407. https: //doi.org/10.1016/j.tvj1.2005.01.006.

Oliver, S. P., R. A. Almeida, B. E. Gillespie, S. J. Headrick, H. H. Dowlen, D. L. Johnson, K. C. Lamar, S. T. Chester, and W. M. Moseley. 2004. Extended ceftiofur therapy for treatment of experimentally-induced Streptococcus uberis mastitis in lactating dairy cattle. J. Dairy Sci. 87:3322-3329. https://doi.org/10.3168/jds .S0022-0302(04)73468-2.

Rainard, P., and C. Riollet. 2003. Mobilization of neutrophils and defense of the bovine mammary gland. Reprod. Nutr. Dev. 43:439457. https://doi.org/10.1051/rnd:2003031.

Tassi, R., T. N. McNeilly, J. L. Fitzpatrick, M. C. Fontaine, D. Reddick, C. Ramage, M. Lutton, Y. H. Schukken, and R. N. Zadoks, 2013. Strain-specific pathogenicity of putative host-adapted and nonadapted strains of Streptococcus uberis in dairy cattle. J. Dairy Sci. 96:5129-5145. https://doi.org/10.3168/jds.2013-6741.

Tassi, R., T. N. McNeilly, A. Sipka, and R. N. Zadoks. 2015. Correlation of hypothetical virulence traits of two Streptococcus uberis strains with the clinical manifestation of bovine mastitis. Vet. Res. 46:123. https://doi.org/10.1186/s13567-015-0268-y.

Varhimo, E., P. Varmanen, A. Fallarero, M. Skogman, S. Pyörälä, A. Iivanainen, A. Sukura, P. Vuorela, and K. Savijoki. 2011. Alpha- and $\beta$-casein components of host milk induce biofilm formation in the mastitis bacterium Streptococcus uberis. Vet. Microbiol. 149:381-389. https://doi.org/10.1016/j.vetmic.2010.11.010.

Wang, S. M., M. A. Deighton, J. A. Capstick, and N. Gerraty. 1999. Epidemiological typing of bovine streptococci by pulsed-field gel electrophoresis. Epidemiol. Infect. 123:317-324. https://doi.org/10 $.1017 /$ S0950268899002745.

Weidenmaier, C., and A. Peschel. 2008. Teichoic acids and related cellwall glycopolymers in Gram-positive physiology and host interactions. Nat. Rev. Microbiol. 6:276-287. https://doi.org/10.1038/ nrmicro1861.

Zadoks, R. N.. B. E. Gillespie, H. W. Barkema, O. C. Sampimon, S. P. Oliver, and Y. H. Schukken. 2003. Clinical, epidemiological and molecular characteristics of Streptococcus uberis infections in dairy herds. Epidemiol. Infect. 130:335-349. 